\title{
The Role and Strategy of Business Administration in the Development of Scientific and Technological Innovation in Enterprises
}

Le Yuan*

Xinxin Taijie Science and Technology Development Co., Ltd. E-mail: yuanle@sina.com

Abstract: The development of enterprises can not be separated from the role of business administration. In order to realize scientific and technological innovation, enterprises should strengthen the level and quality of business administration. Through the reform and innovation of business administration, enterprises can improve their own strength and have sufficient foundation to face the market competition.

Keywords: Enterprise Development; Scientific and Technological Innovation; Business Administration

\section{Introduction}

Under the background of the new era, improving the management ability of industrial and commercial enterprises can promote China's economic development. In today's fierce market competition, enterprises not only need to ensure their own survival skills, but also need to focus on long-term development, constantly reform and innovate their own business philosophy and business model, strengthen their own management level and ability, and have comprehensive strength to stand in the market competition, so as to develop steadily for a long time. As an industrial and commercial enterprise, the first thing to do is to organize an innovative and professional talent team to improve the overall management level. Secondly, they should formulate a sound industrial and commercial management system and mechanism, so that the work of managers can have a certain basis and ensure that the efficiency of management can be steadily improved. In addition, the enterprise's risk management and control ability needs to be improved, and the enterprise managers need to analyze the risks according to the market development trend and their own actual situation, and plan effective avoidance schemes to ensure the healthy and stable development of the enterprise.

\section{The concept and current situation of business administration}

\subsection{Concept}

Business administration refers to the standardized management of the main body and behavior of the market economy according to relevant laws and regulations, so as to keep the orderly and harmonious development of the market economy. Market economy includes all aspects of enterprise management, while administration can inspect market activities and effectively restrain operation behavior, so that enterprises can develop steadily and well in the market. China's industrial and commercial administration has a long history. After the reform and opening up, in order for China's economy to meet the needs of the development of the times and meet the international standards, it constantly carries out innovation and reform, puts forward relevant policies, and establishes an industrial and commercial

Copyright (C) 2020 Le Yuan

doi: 10.18282/bam.v2i2.1551

This is an open-access article distributed under the terms of the Creative Commons Attribution Non-Commercial License

(http://creativecommons.org/licenses/by-nc/4.0/), which permits unrestricted non-commercial use, distribution, and reproduction in any medium,

provided the original work is properly cited. 
administration mechanism with Chinese characteristics. Facing the new situation of economic market transformation at home and abroad, China's market economy, proceeding from reality, gives full play to the initiative of the industrial and commercial system, optimizes the business procedures of enterprises, and promotes enterprises to adapt to the development of the new era and have more substantial strength. The reform and innovation of industrial and commercial management mechanism has a good role in promoting China's economic development, and also brings new opportunities for China’s economic development.

\subsection{The status quo of business administration}

\subsubsection{Inconsistency between the business management concept of the enterprise and the actual development}

China's market economy environment is changing complex, and the competitive pressure is increasing for enterprises, which puts forward new requirements for business administration. Although many enterprises have made corresponding improvements and optimizations according to the actual development situation, there is still a certain gap between the current business administration and the development needs of enterprises. In the process of management, it is deeply influenced by traditional ideas, which leads to the management being more modular, unable to adapt to the production and operation of enterprises, and lacking the courage of innovation and reform, resulting in the failure of industrial and commercial management to play its fundamental role. In carrying out the work, the relevant work is innovated and adjusted without combining with the actual market environment. The overall management thought is relatively backward and lacks certain innovation, which will limit the development of business administration to a great extent and have a negative impact on the management system of enterprises. In addition, the scale of enterprises is constantly expanding, and the industrial and commercial management system is not changed in time, which leads to many loopholes and defects in the management process and affects the development of enterprises.

\subsubsection{Lack of professional talents in business administration}

Business administration plays a very important role in the development of enterprises. Most enterprises will attach importance to the cultivation of business administration talents. However, as far as the development of business administration students is concerned, there are more junior management talents, while middle and senior management talents are relatively scarce. Although the basic knowledge of junior management talents is also very comprehensive, the practical application ability is relatively scarce, and it is impossible to formulate an efficient development plan in combination with the development needs of enterprises in practical work, nor to formulate an appropriate plan for the design of enterprise management activities, which will bring a certain lag to the development of enterprises.

\subsubsection{Single and backward industrial and commercial management system}

With the continuous development of China's economy, the role and function of business administration have been improved to some extent. In this case, business administration is facing new challenges and opportunities, with its scope of work being virtually expanded. Therefore, it is necessary to actively take effective measures to make up for and improve the weak links of business administration and strengthen the advantages. However, the current business administration has always adhered to the principle of different standards in different regions. An enterprise is divided into different regions, and the actual situation of each department is also different, which will promote the work of each department to a certain extent, but it will raise great difficulties for the overall management of the enterprise, and there will also be problems of regional protection. According to China's actual situation, it is necessary to formulate corresponding management policies to promote China’s economic development and push enterprises to internationalization.

\section{The role of business administration in promoting scientific and techno- logical innovation of enterprises}

\subsection{To improve the importance of scientific and technological innovation of enterprises}

Scientific and technological innovation of enterprises can be understood as the development of enterprises, which can directly affect the future development and operation of enterprises, that's why enterprises should pay attention to it. 
While attaching importance to scientific and technological innovation, enterprise managers also need to strengthen employees' attention to innovation. Through training and knowledge contests, they can enhance employees' innovative thinking and construct a good cultural atmosphere for enterprises. From the perspective of enterprise management, enterprises should abide by the principle of comprehensiveness, adopt a correct attitude towards the technological innovation of enterprises, and promote the smooth degree of enterprise innovation in a reasonable and scientific way.

\subsection{To enrich the talent reserve}

The development of talents is the development of enterprises. Only when the skills of talents reach the level of enterprise development can enterprises develop steadily and well. Therefore, to realize scientific and technological innovation, enterprises must strengthen the cultivation and introduction of talents and realize the development of enterprises. They need to introduce relevant talents in business administration to avoid mistakes in major decisions, so that the daily management of enterprises can be carried out smoothly, and the development of enterprises is gradually on the rise. In addition, enterprises also need to strengthen the training of existing employees, carry out courses on scientific and technological innovation, improve their enthusiasm for learning, and provide enough space for their development, so that the overall strength of the enterprise can be developed, and employees can accumulate relatively abundant knowledge reserves and vocational skills, improve their comprehensive strength and overall quality, which is conducive to the management of managers and provides necessary guarantee for scientific and technological innovation of enterprises.

\subsection{The role of enterprise funds}

Scientific and technological innovation can promote the development of enterprises to a certain extent. To realize scientific and technological innovation, it is necessary to invest a lot of time and money, and enough capital is needed to realize the effectiveness of business administration. The investment direction of scientific and technological innovation also includes investment in relevant personnel. Therefore, while increasing project investment, it is also necessary to ensure the improvement of the labor remuneration level of scientific and technological innovation employees, and promote the innovation and reform of employees by means of incentives and rewards, so as to provide power for scientific and technological innovation of enterprises.

\subsection{To strengthen the monitoring of the product quality of enterprises}

Enterprises' scientific and technological innovation is bound to form new scientific and technological products. After the products are produced, it is necessary to carry out technical inspection on the products to ensure that the they have certain effectiveness. However, the mechanical equipment and production technology used by many enterprises can no longer meet the development needs of society, which leads to the backward production of enterprises. Therefore, enterprises should strengthen research, form new scientific research achievements and enhance the production efficiency of enterprises in the process of development, so that scientific and technological innovation products can promote the development of enterprises.

\section{Strategies for optimizing business administration}

\subsection{To strengthen the management and innovation awareness of managers}

Under the background of the present era, enterprises should give full play to their own values and advantages, constantly innovate and optimize their business models, and improve their competitive strength in response to the fierce market economy. Enterprises should strengthen their influence in society and improve their comprehensive strength. The primary task of business administration in enterprises is to establish a standardized management concept for employees of enterprises and strengthen the innovation of management work. Enterprises can combine new management concepts and management methods, so that they can better adapt to social and economic development, seize the favorable factors and conditions for their own development, give full play to their own management advantages, combine in- 
ternal and external enterprises, find problems in time in management, analyze the causes of problems, and then solve problems and improve the efficiency of enterprise management. If an enterprise wants to achieve the purpose of business administration, it is necessary for them to establish perfect management quality and improve management efficiency through institutional constraints. In addition, enterprises also need to do a good job of propaganda to ensure that employees can face their work with a positive attitude, change their own thoughts and devote all their energy to the development of enterprises. Managers should analyze the market economy with new management thinking and analyze their own position in the market, so as to improve the management level of enterprises and ensure that enterprises can develop flexibly.

\subsection{To actively prevent enterprise development risks}

In the process of development and operation, enterprises will be affected by various environmental factors and some other unfavorable factors, leading to slow development and even risks. These factors are uncontrollable and inevitable. Therefore, in order to effectively avoid these problems and reduce the adverse effects of enterprise development, enterprises need to strengthen the consciousness of employees and establish a positive corporate culture in their normal management. To enable employees to have enough sense of responsibility and improve the quality of business administration on the basis of perfecting enterprise rules and regulations, enterprise managers should strengthen the comprehensive implementation of business administration, so that enterprises can effectively avoid and reduce development risks.

\subsection{To reform and innovate staff incentives}

Innovating and reforming the reward system is also an important part of enterprise development. By establishing a reasonable reward mechanism, salary mechanism and promotion mechanism, a good enterprise atmosphere can be created, and the initiative and enthusiasm of employees can be stimulated, thus promoting the development of enterprises to a certain extent. Through the big data of business administration, it can evaluate each employee's working ability, so that employees can fully understand themselves and realize their professional level. The pursuit of interests is everyone's instinctive need. Every employee works to obtain economic resources. In order to obtain economic resources, he puts his own experience into his daily work, hoping that his efforts are directly proportional to his return. Only by respecting the labor achievements of the staff can the employees have strong motivation to work. Therefore, when formulating the assessment system and reward system, enterprises should consider and plan from the perspective of employees to ensure that employees can get the maximum benefits, so as to effectively promote the enthusiasm and enthusiasm of employees. The reward mechanism should be set reasonably according to the employees' comprehensive achievements, be open and transparent, and never take sides. By establishing a perfect reward mechanism, the enthusiasm of employees can be fully mobilized, which is conducive to the smooth development of business administration, and then enhance the development level of enterprises.

\section{Conclusion}

Business administration can promote the scientific and technological development of enterprises. In the process of innovation and transformation of enterprises, it is necessary to give full play to the role of business administration, so as to provide a certain foundation for the development of enterprises, and then promote enterprises to stand firmly in the highly competitive market.

\section{References}

1. Xu Z. Analysis of the importance of business administration in technological innovation of enterprises (in Chinese). Taxation 2018; (12): 129.

2. Luo W. Research on the important role of science and technology innovation in business administration. Economic Management Digest 2019; 733(19): 101-102.

3. Zhu H. Discussion on the role of business administration in promoting technological innovation of enterprises (in 
Chinese). Chinese and Foreign Entrepreneurs 2020; 679(17): 62. 